Methods: Thirty-one patients were enrolled in this study: the group of early SJIA (with duration shorter than 2 years, 19 patients) and the group of late SJIA (with duration longer than 2 years, 12 patients). At the baseline, information was collected on the characteristics of the onset of the disease, previous therapy and its success. At each visit at least 1 time per year clinical and laboratory characteristics of SJIA severity were assessed. Response to therapy was assessed using the ACRPedi 30/50/70/90 criteria and the C.Wallace criteria for inactive disease (WID) and clinical remission.

Results: The most common reason for withdrawal of previous TOC was secondary ineffectiveness (22 cases, $71 \%$ ); in 6 cases (19.4\%) allergic reaction was observed; in two cases (6.5\%) primary non-effectiveness appeared; and in one case $(3.2 \%)$ there was marked infusion reaction.

At CAN initiation, sJIA activity was as follows: 15 (12: 23) for JADAS-71; 45 (36.5: 72) and 58 (45: 81) for physician's and patient's global assessment VAS; and 0.25 (0: 0.62) for the CHAQ disability index.

After 12-month treatment, 22 (71\%) patients reached WID: 21 on CAN therapy and 1 - after CAN withdrawal due to administrative reason and stable WID. ACR50/70/90 response was achieved by $84.2 \% / 84.2 \% / 64.7 \%$ patients in early arthritis group and in $83.3 \% / 75 \% / 75 \%$ patients in late arthritis group $(p=0.792)$.

However, $42.1 \%$ of patients with early SJIA achieved remission in the first 1.5 years without any further relapse during all the studied period and only $16.7 \%$ of patients with late arthritis $(p=0.239)$. In multivariable analysis, it was found that age of SJIA onset (OR $(2.5-97.5 \mathrm{Cl}) 0.353(0.13-0.72), p=0.015)$, number of joints with active arthritis at sJIA onset (2.308 (1.26-5.73), $p=0.025)$, and JADAS71 at SJIA onset $(0.664(0.44-0.88), p=0.016)$ were associated with successful treatment with rapid achievement of stable remission.

During the 76.7 patient-years follow-up period, 18 of $31(58.1 \%)$ patients were able to achieve a stable clinical remission and $27(87.1 \%)$ - WID. Two patients have achieved successfully drug-off remission. Serious adverse event (SAE) was reported in one (3.2\%) patient (enteritis).

Conclusion: Long-term canakinumab therapy proved to be effective and safe as a second biologics after tocilizumab for any duration of the disease. However, patients with early arthritis are more likely to quickly achieve stable remission without further relapse. Younger onset of SJIA with polyarthritis involvement and low disease activity are predictors of rapid and stable remission.

Disclosure of Interests: Ekaterina Alexeeva Grant/research support from: Roche, Pfizer, Centocor, Novartis, Speakers bureau: Roche, Novartis, Pfizer., Elizaveta Krekhova: None declared, Tatyana Dvoryakovskaya: None declared, Ksenia Isaeva: None declared, Aleksandra Chomakhidze: None declared, Evgeniya Chistyakova: None declared, Olga Lomakina: None declared, Rina Denisova: None declared, Anna Mamutova: None declared, Anna Fetisova: None declared, Marina Gautier: None declared, Dariya Vankova: None declared, Meyri Shingarova: None declared, Alina Alshevskaya: None declared, Andrey Moskalev: None declared, Ivan Kriulin: None declared

DOI: 10.1136/annrheumdis-2020-eular.5706

\section{THU0507 ASSOCIATION BETWEEN JUVENILE IDIOPATHIC ARTHRITIS AND AUTISM}

\section{R. Beesley ${ }^{1}{ }^{1}$ Juvenile Arthritis Research, Tonbridge, United Kingdom}

Background: Juvenile Idiopathic Arthritis (JIA) is a heterogenous group of autoimmune disorders characterised by chronic joint inflammation, diagnosed in around 1 in 1,000 children and young people (CYP) under the age of 16. Autistic Spectrum Condition (ASC) is a neurodevelopmental condition characterised by differences in social communication and sensory perception, as well as restricted interests and repetitive behaviours. Recent estimates from the Centers for Disease Control and Prevention (CDC) suggest that $1.68 \%$ of CYP are diagnosed with ASC, with males being more likely to be diagnosed (sex ratio of $4: 1$ ) [1]. The causes of both JIA and ASC are complex interactions between genetic and environmental factors. There appears to be some evidence that ASC may be associated with certain parental autoimmune conditions [2], although research into any association between JIA and ASC is sparse with the exception of a review of clinical database information [3].

Objectives: In this parent-led study, the association between JIA and ASC was explored in order to determine if children with JIA, or children who do not themselves have JIA but have at least one first-degree relative with JIA (FDR), are more likely to be diagnosed with ASC.

Methods: Parents of CYP with JIA were invited to complete an online survey, giving details of each member of their family including diagnosis status for JIA and ASC, and age of diagnoses. A total of 247 responses were collated, representing 558 CYP. Overall, 202 CYP were diagnosed with JIA from 197 families. The eldest child with JIA from each family was selected (total 197; 66 male and
131 female) and the rate of ASC was compared against the general population using Fisher's exact tests.

Results: Children with JIA themselves and FDR children were significantly more likely to be diagnosed with ASC.

\begin{tabular}{llll}
\hline Group & Odds Ratio $(95 \%$ Cl) & p-value & \\
\hline JIA children overall & $6.107(1.760,21.190)$ & 0.0020 & $\star \star$ \\
FDR children overall & $7.009(2.033,24.160)$ & 0.0006 & $\star \star \star$ \\
\hline
\end{tabular}

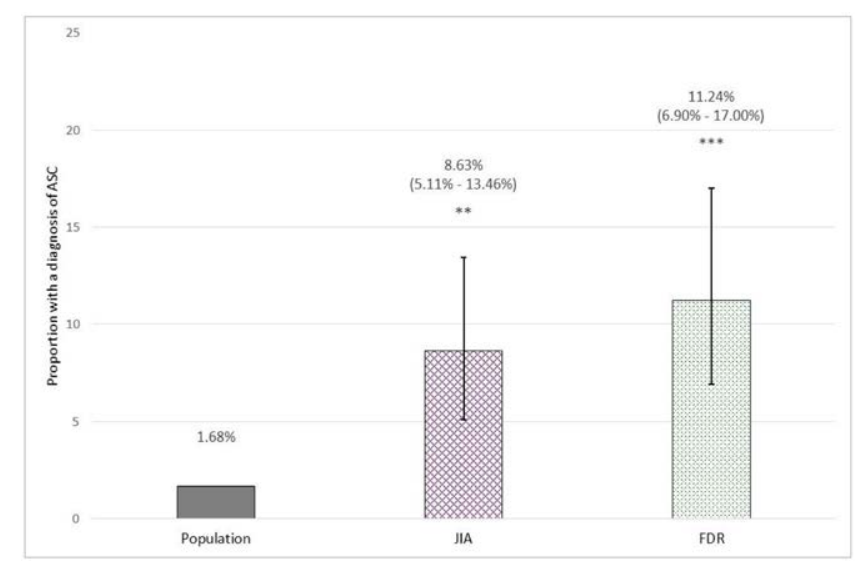

Figure 1. Proportion of children diagnosed with ASC in the general population (CDC estimates), JIA group and FDR group. Error bar indicates $95 \% \mathrm{Cl}$. Significance indicated compared to population.

Conclusion: Individuals with JIA and family members of individuals with JIA are more likely to be diagnosed with ASC. The results remained unchanged in a sensitivity analysis in which JIA children who had another sibling with JIA were excluded in order to minimise the risk that these results were affected by selecting the eldest child with JIA.

It is possible that we are underestimating the association between JIA and ASC in this study. The majority of children sampled were from the United Kingdom and Ireland; however, we chose to utilise the most recent CDC estimates for ASC prevalence, as the most recent estimates from the UK were from 2006 and longitudinal data suggests that ASC prevalence continues to increase, likely due to changes in diagnostic criteria and improved recognition of the condition. When using the UK prevalence estimates, JIA children and FDR children remain significantly more likely to be diagnosed with ASC than the general population as a whole.

Future research should focus on confirming these findings in larger, population-based samples.

\section{References:}

[1] Christensen DL, Braun KV, Baio J, et al. Prevalence and Characteristics of Autism Spectrum Disorder Among Children Aged 8 Years - Autism and Developmental Disabilities Monitoring Network, 11 Sites, United States, 2012. MMWR Surveill Summ (2018); 65 (No. SS-13):1-23.

[2] Hughes, H. K., Mills Ko, E., Rose, D. \& Ashwood, P. Immune Dysfunction and Autoimmunity as Pathological Mechanisms in Autism Spectrum Disorders. Frontiers in Cellular Neuroscience (2018); 12

[3] Haslam, K. P16 Is there an association between paediatric rheumatological disease and autism? Rheumatology 2019; 58

Disclosure of Interests: None declared

DOI: 10.1136/annrheumdis-2020-eular.876

\section{THU0508 \\ LARGE VESSEL VASCULITIS IN A COHORT OF CHILDREN WITH RESISTANT KAWASAKI DISEASE IN SINGAPORE}

$\underline{\text { L. Das }}^{1}$, J. H. T. Tan ${ }^{1}$, T. Arkachaisri ${ }^{1,2} .{ }^{1}$ KK Women's and Children's Hospital, Rheumatology \& Immunology, Singapore, Singapore; 'Duke-NUS Medical School, Singapore, Singapore

Background: Kawasaki Disease (KD) is one of the most common systemic vasculitidies in children today. IVIG is the mainstay of treatment, however, about $1 / 5$ of patients do not respond resulting in an increased risk of Coronary Artery Abnormalities (CAA) ${ }^{1}$. 
Objectives: To describe a cohort of infants and young children with resistant Kawasaki Disease ( $r K D$ ) who were noted to have prolonged difficult courses with resultant CAA and ultimately diagnosed with Aortitis.

Methods: Demographic, clinical manifestations and imaging data were collected from children seen in Rheumatology clinic with a diagnosis of rKD and aortitis. Nonparametric descriptive statistics were used to describe the data.

Results: Between 2010-2018, 63 out of 417 KD referrals were diagnosed with rKD. 7 children had prolonged time to CRP normalisation, prolonged admission or recurrence of symptoms (Table 2). All patients underwent Magnetic Resonance Angiography (MRA) and were found to have evidence of large vessel arteritis consisting of wall irregularity, thickness and contrast enhancement.

Table 1

ID Age at Number BCG site Lowest Highest \#Highest Highest Lowest Maximum Maximum diag- of clinical inflam- Hemoglobin WBC Platelet CRP Albumin ALT AST nosis KD mation g/DL $10(9) \mathrm{L} 10(9) \mathrm{L} \quad \mathrm{mg} / \mathrm{L} \quad \mathrm{g} / \mathrm{L} \quad \mathrm{U} / \mathrm{L} \quad \mathrm{U} / \mathrm{L}$ (mo) signs $^{\star \star}$

\begin{tabular}{ccccccccccc}
\hline A & 31 & 3 & 0 & NA & NA & NA & NA & NA & NA & NA \\
B & 7 & 4 & 0 & 9.5 & 37.3 & 875.0 & 206.0 & 21.0 & 36.0 & 32.0 \\
C & 4 & 4 & 1 & 9.8 & 43.2 & 918.0 & 130.0 & 22.0 & 44.0 & 52.0 \\
D & 3.5 & 4 & 1 & 9.2 & 42.4 & 1715.0 & 181.4 & 18.0 & 61.0 & 99.0 \\
E & 5 & 4 & 1 & 6.7 & 17.6 & 1413.0 & 148.2 & 27.0 & 20.0 & 24.0 \\
F & 2 & 3 & 0 & 6.4 & 35.6 & 959.0 & 212.1 & 15.0 & 8.0 & 19.0 \\
G & 24 & NA & NA & 8.6 & 21.9 & 1002.0 & 181.4 & 27.0 & 17.0 & 30.0 \\
\hline
\end{tabular}

5 patients were male; All were Singaporean Chinese except for $G$ who was from the Philippines; A \& G were treated in an outside facility/separate service initially and some data was not available; \# Blood test results were generally taken at the same time apart from the platelet count; **Only D presented with lymphadenitis.

\section{Table 2}

\begin{tabular}{|c|c|c|c|c|c|c|}
\hline ID & $\begin{array}{l}\text { Tlme to } \\
\text { CRP nor- } \\
\text { malization } \\
\text { (weeks) }\end{array}$ & $\begin{array}{l}\text { Number } \\
\text { of IVIG } \\
\text { given }\end{array}$ & Steroids & $\begin{array}{l}\text { Time to } \\
\text { abnormal } \\
\text { echo } \\
\text { (weeks) }\end{array}$ & $\begin{array}{l}\text { Time to } \\
\text { aneurysm } \\
\text { development } \\
\text { (weeks) }\end{array}$ & Other outcomes \\
\hline A & * & 2 & oral only & 4 & 4 & $\begin{array}{c}1^{\text {st }} \text { IVIG given } 3 \text { weeks after } \\
\text { symptom onset }\end{array}$ \\
\hline B & * & 2 & IV/PO & 2 & 2 & $\begin{array}{l}\text { deceased, MI secondary to } \\
\text { thrombus }\end{array}$ \\
\hline C & 2 & 1 & IV/PO & 1.1 & 0 & $\begin{array}{l}\text { treated with Infliximab and } \\
\text { then Methotrexate, } \\
\text { post infliximab psoriasis, }\end{array}$ \\
\hline D & 5 & 1 & IV/PO & 0.3 & 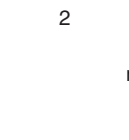 & $\begin{array}{l}\text { treated with Infliximab and } \\
\text { then Methotrexate, } \\
\text { multiple infections in hospital; } \\
\text { BCG reactivation while on } \\
\text { Infliximab }\end{array}$ \\
\hline$E$ & 9 & 2 & no & 1.4 & 2.7 & UTI, AIHA, lost to follow up \\
\hline $\mathrm{F}$ & 3 & 3 & IV/PO & 0.71 & 2.5 & $\begin{array}{l}\text { post Infliximab psoriasis, mul } \\
\text { tiple infections in hospital }\end{array}$ \\
\hline G & 7 & 2 & oral only & 7 & 0 & lost to follow up \\
\hline
\end{tabular}

*patients A \& B had recurrent KD episodes interspersed with short periods of symptom resolution

Conclusion: While transthoracic echocardiograms remain imaging investigation of choice, for children with recalcitrant or recrudescent KD, especially in the setting of delayed CRP resolution of $>2$ weeks; an MRA should be considered.

References:

[1] McCrindle BW, Rowley AH, Newburger JW, et al. Diagnosis, Treatment, and Long-Term Management of Kawasaki Disease: A Scientific Statement for Health Professionals From the American Heart Association. Circulation. 2017 Apr 25;135(17):e927-e999.

Disclosure of Interests: None declared

DOI: 10.1136/annrheumdis-2020-eular.1646

\section{THU0509 IMPACT OF PEDIATRIC RHEUMATIC DISEASES ON MEXICAN CAREGIVERS.}

B. Fortuna ${ }^{1}$, I. Peláez-Ballestas ${ }^{2}$, F. García-Rodríguez ${ }^{3}$, E. Faugier ${ }^{4}$,

S. Mendieta ${ }^{5}$, A. V. Villlarreal ${ }^{1}$, S. Rosiles ${ }^{1}$, G. Reyes ${ }^{6}$, S. Jimenez ${ }^{1}$,

J. Guadarrama ${ }^{4}$, N. Rubio ${ }^{1}$. 'Universidad Autónoma de Nuevo León, Monterrey,

Mexico; ${ }^{2}$ Hospital General de México Dr Eduardo Liceaga, Mexico, Mexico;

${ }^{3}$ Universidad Autonoma de Nuevo León, Pediatrics, Monterrey, Mexico;

${ }^{4}$ Hospital Infantil de México Federico Gómez, Mexico, Mexico; ${ }^{5}$ Instituto de Segurodad Social del Estado de México y Municipios, Toluca, Mexico;

${ }^{6}$ Hospital de Especialidades de Chihuahua, Chihuahua, Mexico
Background: Pediatric rheumatic diseases (PRD) have an important impact on different aspects of the patients' and caregivers' life, such as physical, emotional, economic, and social. Some studies have shown that parents of patients with PRD have important impact but there is a lack of information of this topic from Latinamerican countries.

Objectives: The aim of this study is to describe and analyze the impact of juvenile idiopathic arthritis (JIA), juvenile systemic lupus erythematosus (JSLE), and juvenile dermatomyositis (JDM) on Mexican primary caregivers.

Methods: This is a multicenter cross-sectional study conducted in third-level ref erence pediatric hospitals in Mexico from December 2018 to November 2019. We included primary caregivers of pediatric patients with JIA, JSLE, and JDM that were treated in participant centers.

CAREGIVERS questionnaire, a validated multiassesment tool to measure the impact of PRD on caregivers, was applied to the participants. Collection of social demographic, and clinical data was also performed and correlated with questionnaire results.

Results: A total of 200 primary caregivers participates in the study (109 JIA 28 JDM, and 63 JSLE), aged 38 (IQR $32-46$ ), mostly women (84.5\%), from 6 centers, representing 13/32 Mexican states (Figure). One third (78) had a remunerated job, $123(61.5 \%)$ had a relationship, $77(38.5 \%)$ reached high school or higher, and $131(65.5 \%)$ spends more than one hour to get to the center. Patients cared aged 12 (IQR 9 - 16), mostly women (67\%), 87 (43.5\%) with active disease $43(21.5 \%)$ with any disability, $94 \%$ and $29 \%$ treated with DMARD and biologics, respectively.

Feelings of worry and sadness predominant at diagnosis that decreased over time $(42.5 \%$ and $28.5 \%$ vs $9.5 \%$ and $31.5 \%$, respectively) and changed fo peace (44\%). Concerns about disabilities were more frequent on JIA group $(34 \%)$, while pain and economic issues in JSLE (47\% and $30 \%$, respectively. Most of the caregivers feel anxiety about the future of their patients (148, 74\%), regardless of the diagnosis. Participants reported that the way they spend the time, social life, and personal health worsened since diagnosis $(49.5 \%, 32 \%$, and $34.5 \%$, respectively), especially in those with JSLE $(60 \%, 39 \%, 46 \%)$. In $126(63 \%)$ participants the economic situation worsened, 129 (64.5\%) borrowed money (76\% in JSLE, $\mathrm{P}=.03), 63(31.5 \%)$ had problems to buy medications, and $48.5 \%$ have had problems at work. In 25 (12.5\%), the family relationship was affected after diagnosis, however, the main supportive network reported were family members.

Conclusion: This work described the main impacted areas in life of primary caregivers of patients with $\mathrm{PRD}$, showing a perspective of the burden of the disease.

\section{References:}

[1] Cohen EM. Pediatr Rheumatol [Internet]. Pediatric Rheumatology; 2017;15(1):6

[2] Torres-Made. Pediatr Rheumatol 18, 3 (2020).

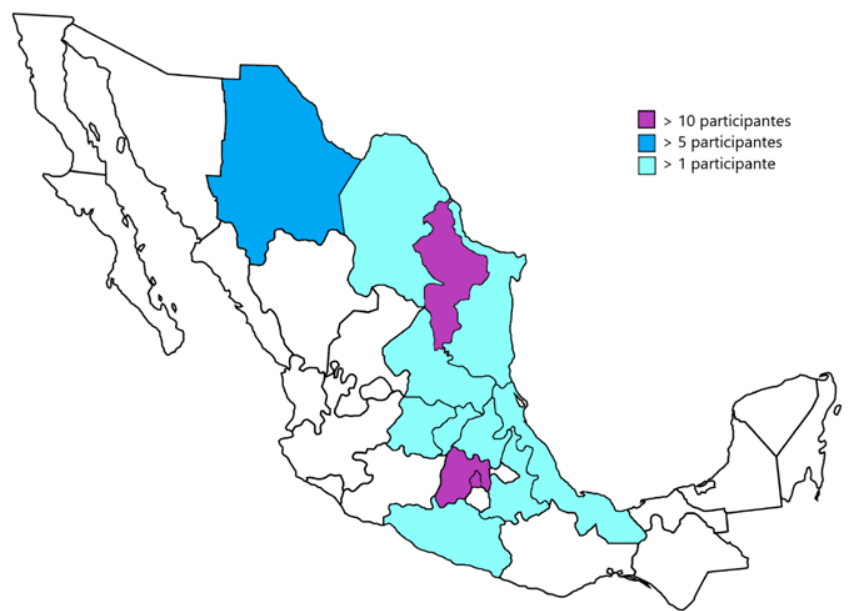

Disclosure of Interests: None declared DOI: 10.1136/annrheumdis-2020-eular.6436

\section{THU0510 COMBINATION. THE NEW FACE OF ACUTE RHEUMATIC FEVER}

G. Aiello ${ }^{1}$, M. A. Prioli ${ }^{2}$, E. Giacomelli ${ }^{1}$, E. Tadiotto ${ }^{1}$, G. Melotti ${ }^{1}$, M. Maschio ${ }^{1}$, M. Pilati ${ }^{2}$, L. Rossetti ${ }^{2}$, F. Caldonazzi ${ }^{3}$, G. Piacentini ${ }^{1}$, S. Pieropan ${ }^{1} .{ }^{1}$ Azienda Ospedaliera Universitaria Integrata Verona, Pediatrics, Verona, Italy; ${ }^{2}$ Azienda 